\title{
PALAZZO DUCALE OF SABBIONETA ARCHITECTURAL SURVEY OF SOME DECORATED ROOMS
}

\author{
A. Bianchi ${ }^{1}$, M. Belloni ${ }^{1}$ \\ 1 alessandro.bianchi@polimi.it; a.mattiabelloni@gmail.com; \\ Dipartimento di Architettura e Studi Urbani, via Bonardi 3, 20133 Milano Italy
}

KEY WORDS: Heritage, Photo-modelling, Architecture, Survey

\section{ABSTRACT:}

Sabbioneta is a small town situated in the province of Mantova, in northern Italy. Founded by Vespasiano Gonzaga Colonna in the XVI century, it constituted the capital of the Sabbioneta Ducat. His specific historical background and renaissance urban fabric made it enter into the UNESCO's World Heritage list in 2008. Other than the economic and political consequences of this event, it shows the architectural importance of Sabbioneta and its great potential for future developments. Palazzo Ducale (Figure 1) was one of the first constructions of the new town. Acting as a ducal residence in its beginnings, its function has evolved over time until the current situation: an exposition space.

\section{INTRODUCTION}
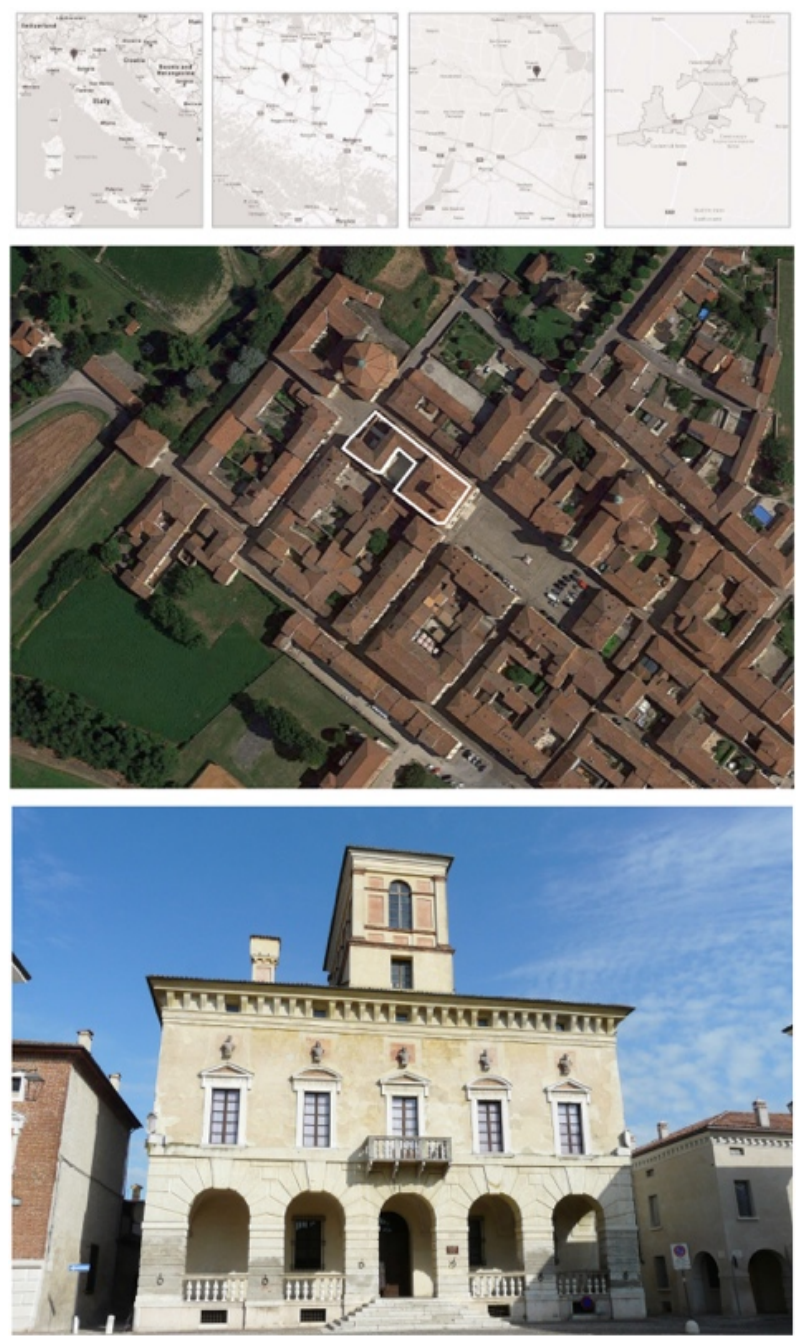

Figure 1. Sabbioneta in Italy, from the google earth, and main façade of Palazzo Ducale

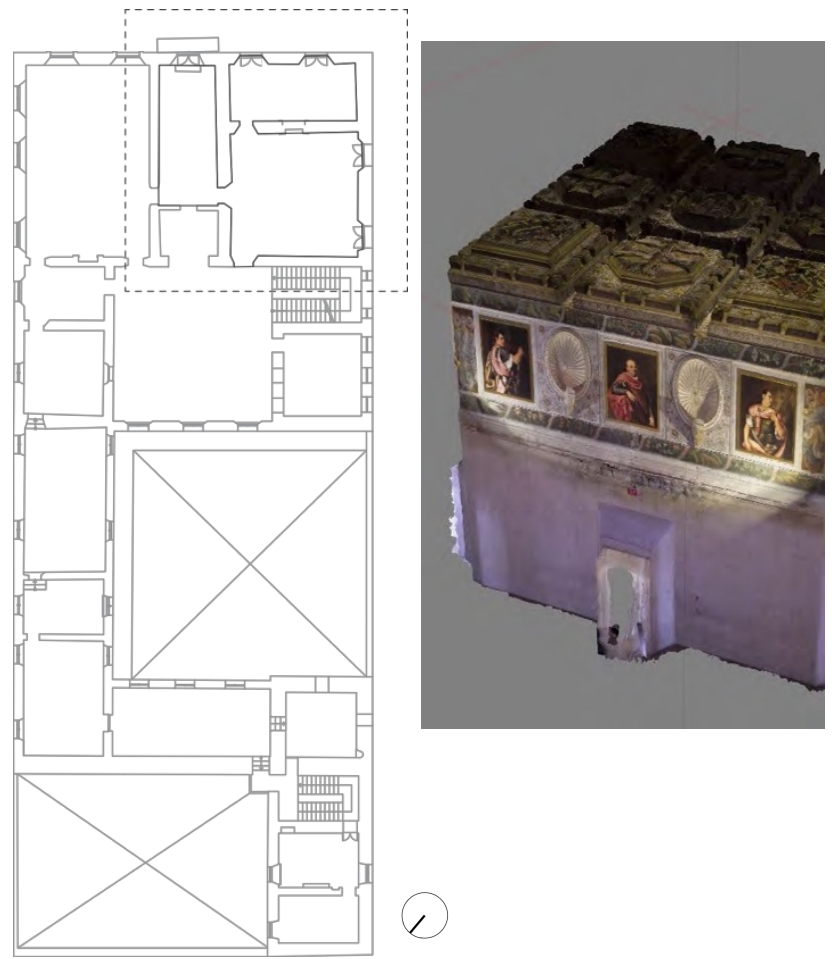

Figure 2. First floor of Palazzo Ducale with surveyed rooms and Photoscan screenshot of the Sala degli Imperatori

Photogrammetry is that discipline which falls within the sphere of indirect instrumental survey, through which it is possible to reconstruct the geometrical form of a territorial, urban or architectural context, through one or more photographic images. Most of the reconstructions of buildings with particular historical value constitute a challenge both on a practical and a representative level, considering the complexity of the artefacts and the quantity of details that often, if not always, compose them.

The term photo-modelling instead is born to define a threedimensional modelling method automated system based on photogrammetric and stereo-photogrammetric surveying systems performed through digital capture and processing of photo sets. 
The procedure for obtaining a model of an existing object consists in taking a series of photographs of the object from different points of view, load them into a special software, process them through a series of automated algorithms, so get a three-dimensional model complete with texture.

The reconstruction of the object can be obtained by following an approach composed of the following operations: calibration of the camera, extraction of points, orientation of the images (pairing of the points), surface reconstruction, surface interpolation, texture mapping, digital archiving, display. Each step must be critically verified by the operator before proceeding with the subsequent to obtain the best possible result.

To better understand the method illustrated in this article, the survey of Palazzo Ducale di Sabbioneta was examined, in particular three rooms (Figure 2), the most representative of the method used to return these in the totality of detail that characterizes them (Figure 3-4).

The surveyed rooms are located in the 1st floor of the Palazzo Ducale, in the south-east corner.

Regarding the circulations, the rooms are situated in the entrance of the 1st floor, just after the stairs.

They face the square in one side and the "statues room" followed by the big courtyard into the other.

Due to its location, the rooms \#03 and \#02 have a direct incidence of southern natural light during the day which make them fully illuminated. They also face the Piazza Ducale. In the other hand the room \#01 is poorly illuminated and facing a narrow street. Depending on the building's function these features should be taken into consideration in order to provide comfortable interior spaces.

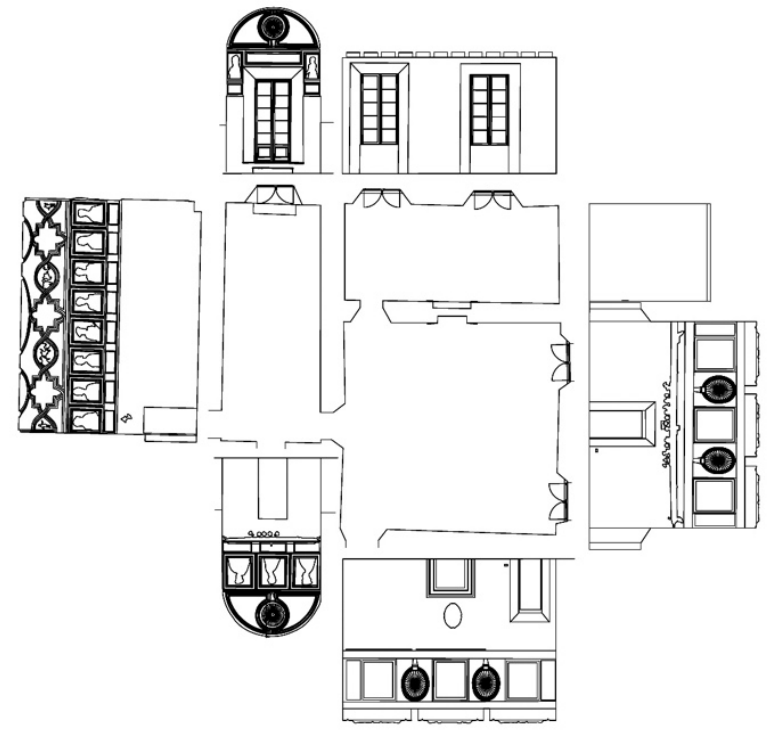

Figure 3. Internal elevations (sections) of the 3 rooms

\section{RELATED WORKS}

As regards works similar to those proposed in this article, it was considered appropriate to indicate some reference texts below for authors who develop, from a theoretical and practical point of view, methodologies useful for surveying interiors of historical monuments. Please refer to the general bibliography the completeness of the bibliographic references on the topic.

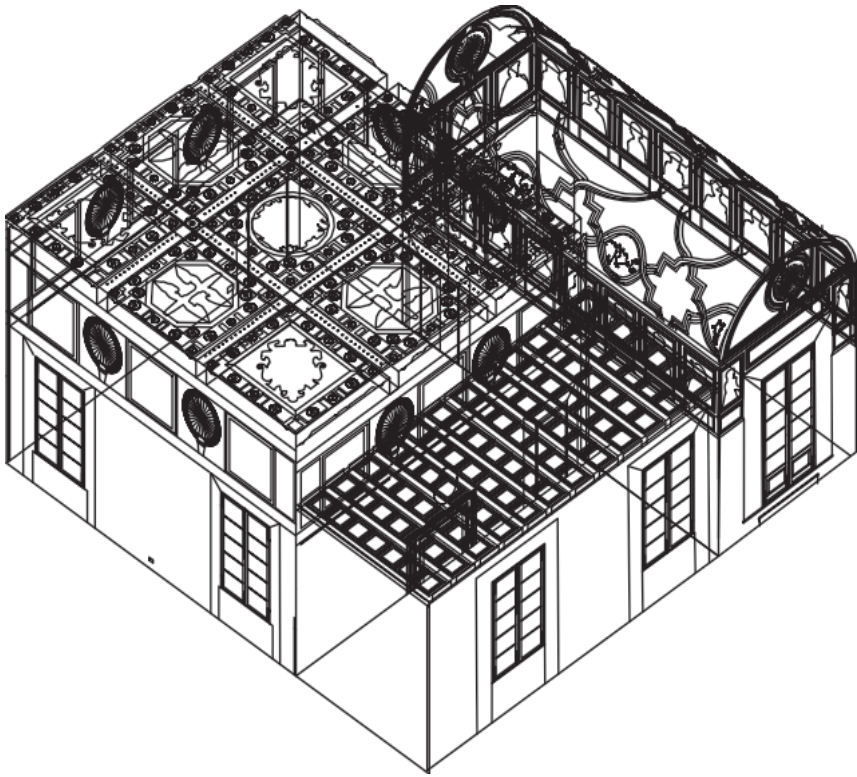

Figure 4. Axonometric view in wire drawing

We can quote L. De Luca (De Luca, 2011), where the author says that the $3 \mathrm{D}$ digitization of heritage is a topical issue for many countries, museums, historical monuments, archaeological sites and other institutions are strongly interested in archiving and digital enhancement. The quoted text is accompanied by three case studies: Villa Savoye by Le Corbusier, Hôtel de BéthuneSully in Paris, chapel of the frescoes of the Certosa di Villeneuvelez-Avignon, which appeal to Image Modeller software's. In the essay by F.I. Apollonio, (Apollonio et al., 2012), they present a BIM-based approach for the documentation of architectural heritage, and where knowledge of classical architecture is first extracted from the treatises for parametric modelling in object level. We can follow this description with the paper by L. Cipriani, (Cipriani et al., 2014), where the topic is to point out the importance of controlling models parameterization process, considering that automatic solutions included in these modelling tools can produce poor results in terms of texture utilization. Another interesting work about this theme is the contribute of S. Di Tondo (Di Tondo and Fabrizi, 2013), where the authors say that with the rescue of the Abu Simbel temples it was possible to experiment with the contemporary photo modelling tools starting from the original data of the photogrammetric survey conducted in the 50 s of the 20th century; this has triggered a reflection on the methods and techniques of "Image Based" modelling, comparing rigorous $3 \mathrm{D}$ digital photogrammetric systems with the current "Structure From Motion" (SFM) systems. At the end a recent paper by C. Battini (Battini and Vecchiattini, 2018) where the scholars present an experiment that provides a pipeline for the creation of HDR images starting from single shots saved in files RAW. The authors take the example of survey of the Cripta dell'Abbazia di San Matteo a Genova, a interior historical space with no natural light, just artificial, and a lot of problems of representation in terms of decorations and architectural details. The above references have been followed by the authors of this paper as guide lines and technics for the developing of the survey on the historical rooms of Palazzo Ducale at Sabbioneta. 


\section{SURVEY PROCESS: WORKFLOW}

The survey process has been done in 5 stages:

1) On site survey

The survey on site starts with the retrieval of all the measuring instruments useful and necessary to get a general picture of the subject matter of the survey, as laser distance meter, metal meter and rib meter, accompanied by instruments such as camera and tripod, to be able to perform measurements of the interior spaces and take the photographs necessary in the later stages.

The measurements must necessarily follow an operations order, starting from:

- Consecutive linear measurements of the walls.

- Measurement through internal triangulations, starting from the establishment of fixed points in the space inside the rooms, called "stations", from which to make measurements and check the squareness and regularity of the walls, often not perfect but irregular, especially if the building in the object has not recent origins if not ancient.

- Monitoring of measurements by digital digitization of the same on the Cad model.

The photographs must be made as much as possible orthogonal to the observer's plane, ortho-photo. This makes possible a subsequent and more accurate image processing through the Photoscan software.

Often the greatest difficulty arises in the moment in which the spaces to be surveyed do not pre-empt from obstacles that prevent the taking of measures from the measuring stations, or that do not make photographic survey of the fronts easy. In this case, indirect measurements, the construction of several measuring stations and the taking of photographs that are not perfectly orthogonal to the observer's visual plane, make it possible to later create the 2D $\mathrm{CAD}$ model and a post-production of the photographs, useful for the subsequent phases of the process of elaboration.

\section{2) Photoscan processing}

Realization of the 3D Models of the rooms using Agisoft Photoscan software.

This part of the process starts with image processing through image editing software (Photoshop), images that should necessarily be in digital RAW format, that preserves all the data related to color, exposure, brightness, shadows and above all white and blacks, in order to balance these images and make them correspond to the reality, and not related to the color profile of the software used for image processing.

Photoscan, once the images are adjusted and loaded onto the software, uses recognizable points of the fronts from the photographs elaborated to reconstruct in 3D the internal (or external) spaces of the survey through the use of photographs. Inside the software, the main parameters of simulations are: "High" photo alignment, "High" Dense cloud composition, "Custom=1,5000,000" faces for mesh generation.

The software processes a cloud of points that builds the detected spaces in the three dimensions. This point cloud can then be used later by software able to process it by creating a "mesh" of these points, thus obtaining a three-dimensional model that can be measured and reconstructed in the desired scale.

\section{3) Post processing}

Using Photoscan's "Ortho-mosaic" workflow all the elevations of the rooms interiors have been obtained. The images have been then post-processed using Photoshop.
The result is a workable and editable 3D realistic model useful for the next steps of the process, or as it is according to a have an idea of the proportion and details present in the surveyed rooms. 4) CAD drawings

Plans and Sections drawn using AutoCAD and following the onsite measurements and ortho-photos.

This step represents the basis for any kind of elaboration of a graphic elaboration and / or subsequent intervention on the built by the operators of the sector.

The previous reconstruction of the environments, through the eidotypes made on site, passes at this point a phase of consolidation of the works and subsequent implementation, through the addition of the details reconstructed through images created through Photoscan.

\section{5) Layout}

In order to obtain the maximum result, the elaborates are processed and represented in big format panels for detailed 1:20 scale sections and summary book for brief overview of the work done.

The main problems encountered during the process have been related to the obtaining of high quality photos during the survey (due to the poor light), the respect of the original features of the surfaces during the post processing and the accurate draw of the CAD documents.

\section{GENERAL PLAN AND VISUALIZATIONS}

The three surveyed rooms present a rectangular plan but different proportions: while room \#01 (Figure 6). is close to a square shape, \#02 and \#03 are very rectangular (Figure 5).

Moreover, due to its position and dimensions the \#02 room spatially occupies a secondary role in the group.

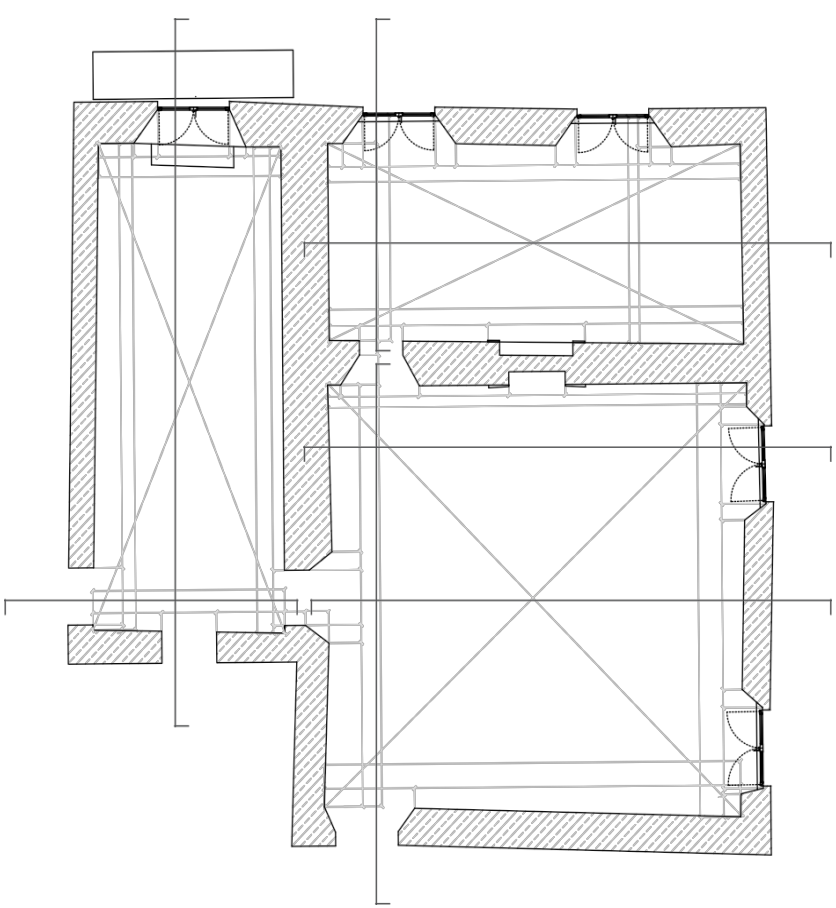

Figure 5. Surveyed plans with section signs of the 3 rooms 


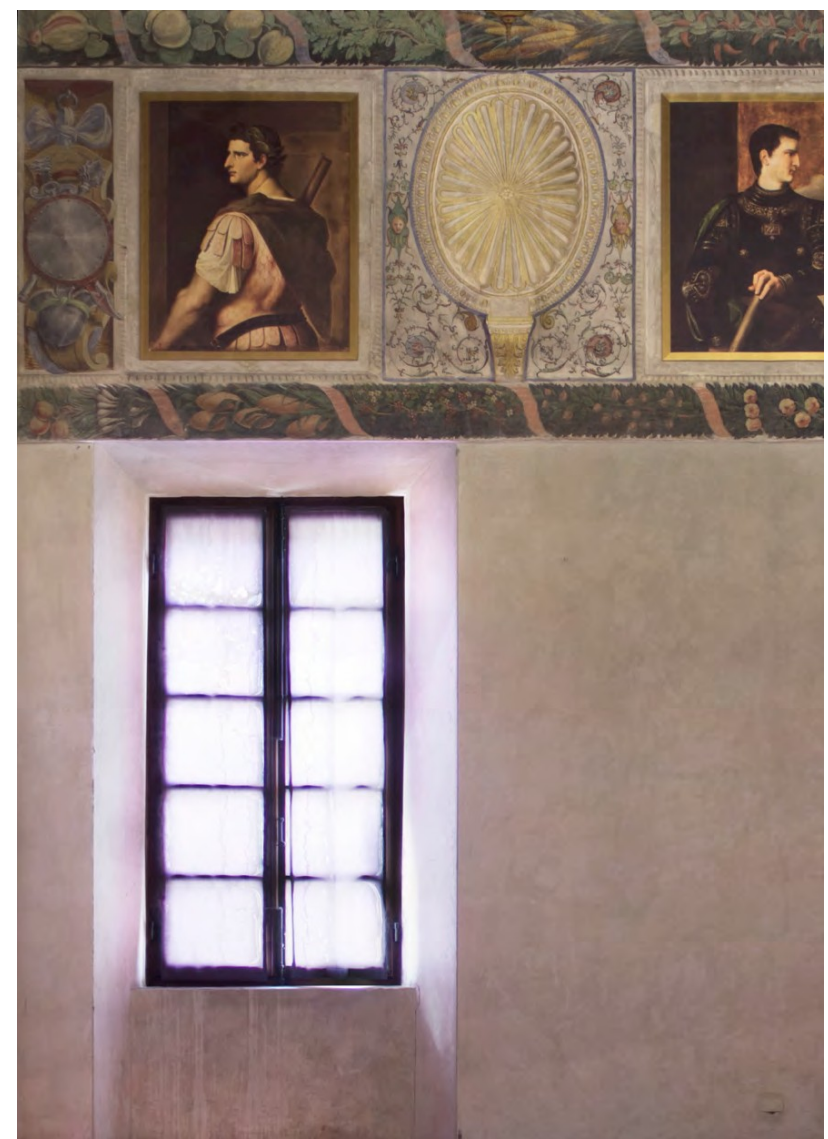

Figure 6. Details of the room coming from Photoscan projections

\subsection{Sala degli Imperatori}

\section{ROOM \#01}

The Sala degli Imperatori (Figure 7-8-9-10) presents a very diverse ornamentation. While the lower part of the walls is covered with white textured plaster, the upper one presents a series of motifs, canvas and sculptural elements. Moreover, the roof is composed of an elaborated mosaic of carved wood and rectangular beams. The representation of roman emperors was in fact a very common ornamentation in the ducal houses of the period. The room has been subjected to a study and subsequent restoration since 2015 .

It currently presents a series of paintings on the walls added from those preserved in the National Museum Capodimonte of Naples and the paintings of 1568 by the artist Ippolito Andreasi, who cover frescoes from different vases and glasses. The rosettes have pedestals, now empty, that housed a series of busts.

As a result of the restoration, the roof has very vivid colors so you can appreciate a great detail, becoming one of the most important spaces of Palazzo Ducale.

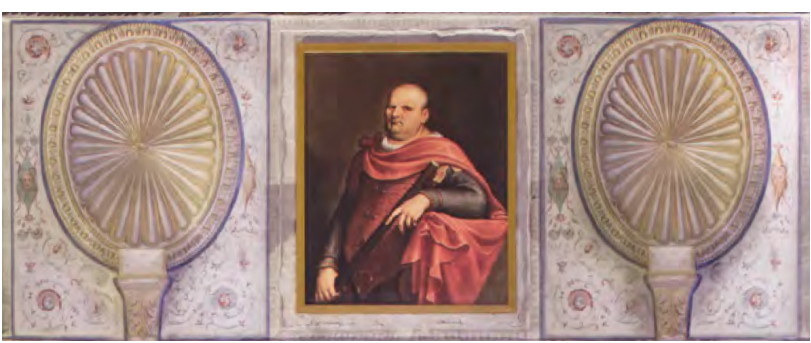

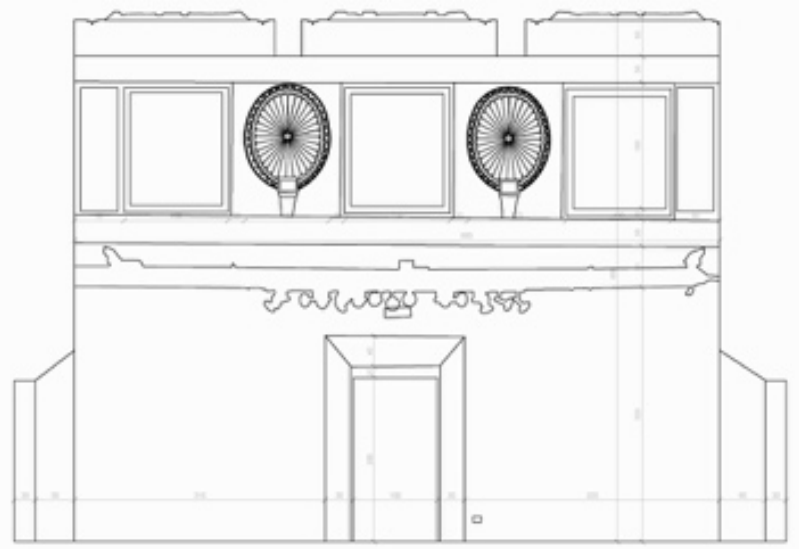
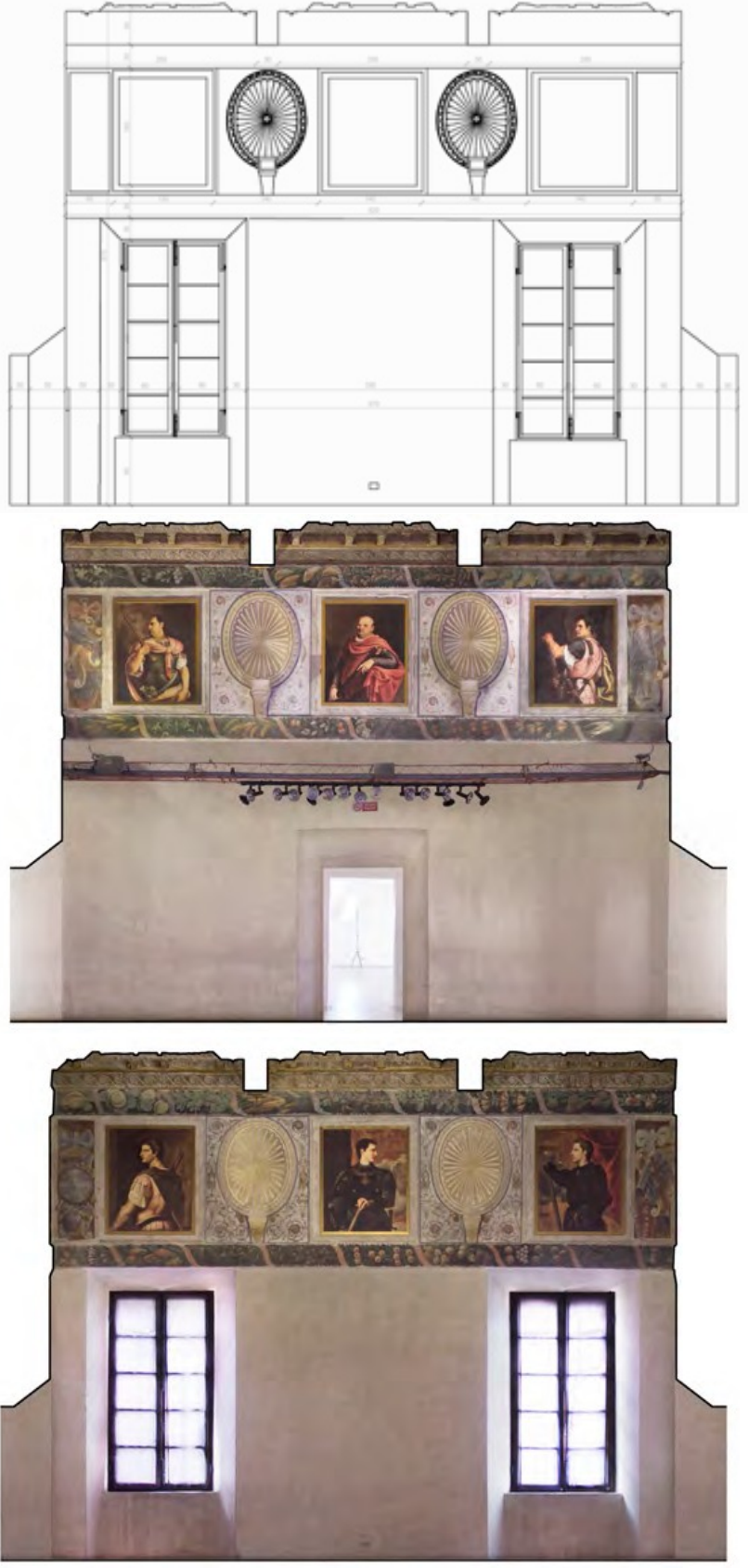

Figure 7. Details and sections of the room (by photos and by lines) coming from Photoscan projections 

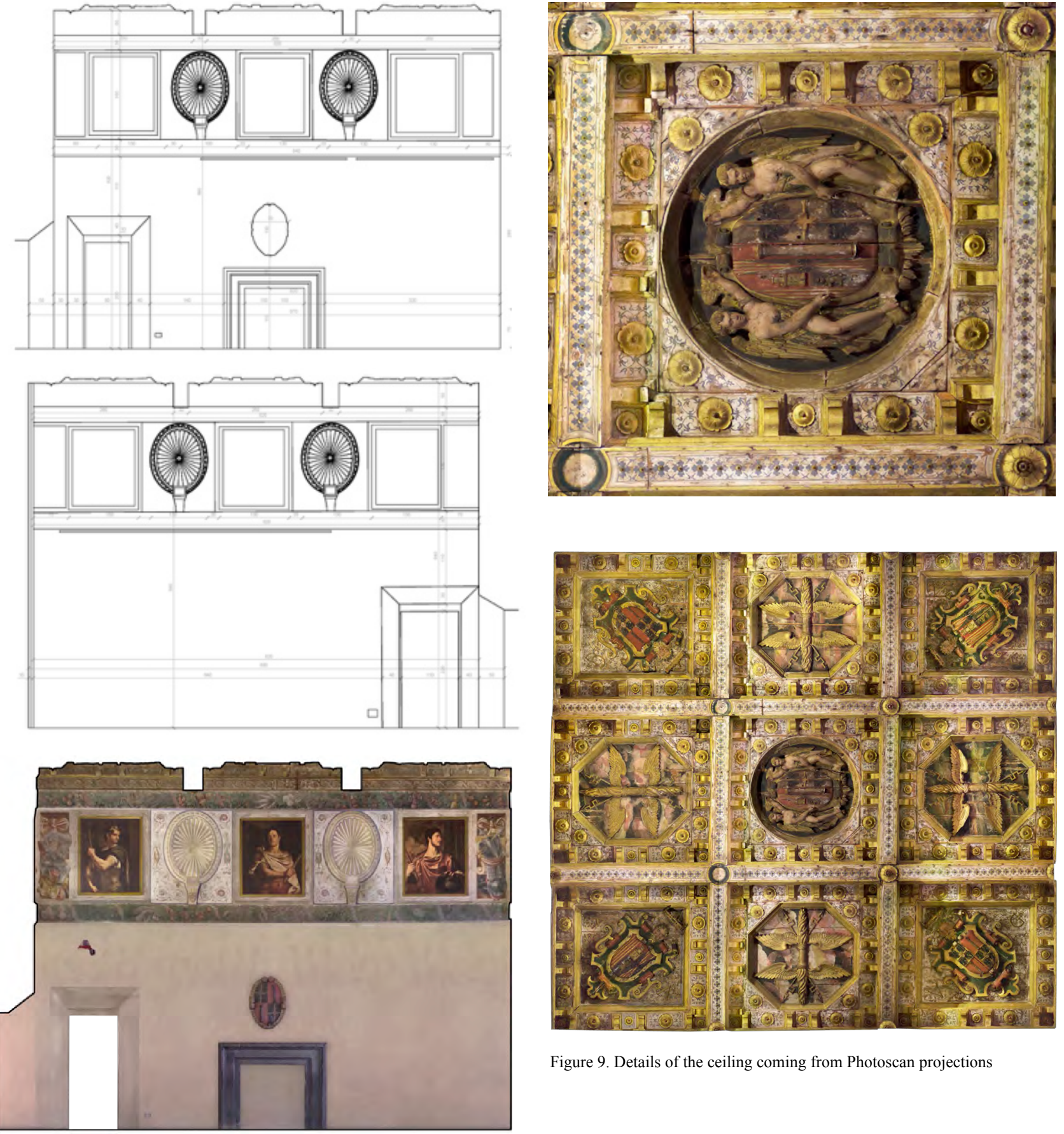

Figure 9. Details of the ceiling coming from Photoscan projections
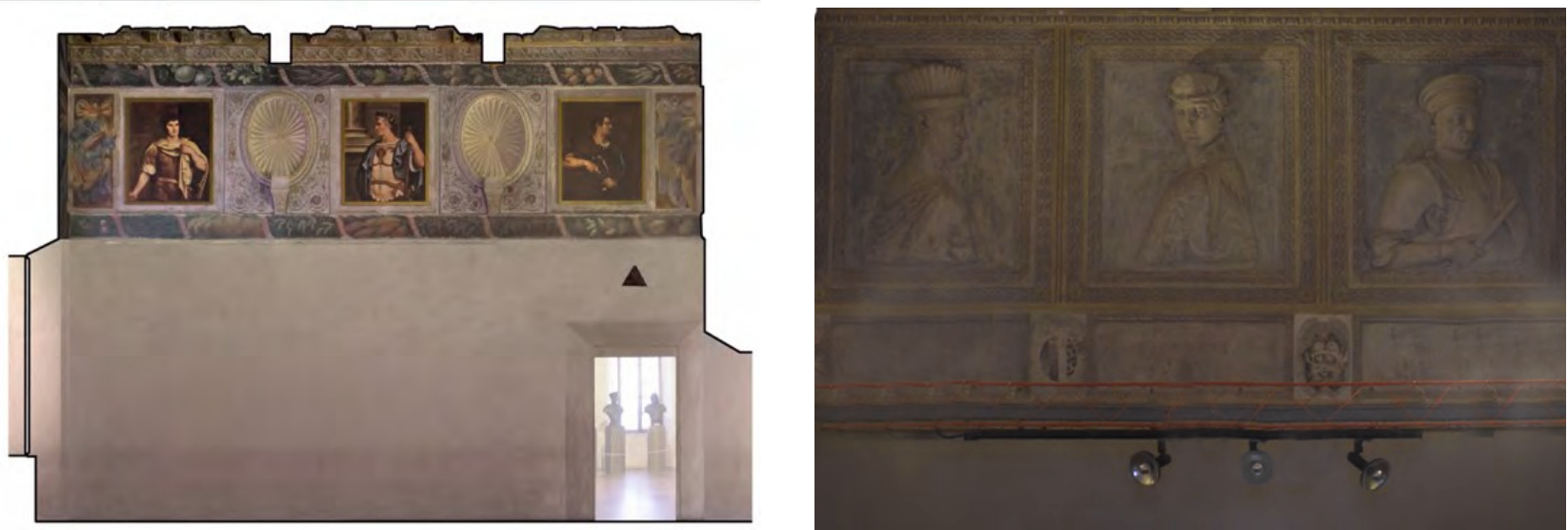

Figure 8 . Sections of the room (by photos and by lines) coming from Photoscan projections

Figure 10. Details of the room and ceiling coming from Photoscan projections 
a) Lighting spots: being supported by a orange steel structure, provide incoherent light to the space and create a visual noise.

b) Wall's plasters: anciently covered by an elaborated carpet, the walls present a much sober aspect. This however highlights the canvas and ceiling composition while creating a defined and sharp volume.

c) The Canvas: it gives unity to the composition and work with the whole ornamentation.

d) The chimney and the shield are also part of the ornamentation and contrast with the homogeneity of the walls.

e) The motifs are arranged in a strong geometrical way: inserted into a $3 \times 3$ grid and inside a basic polygonal shape. The colorful composition, using gold as a primary color gives a sense of nobility to the place.

f) Some ornaments are missing and the wood seems damaged at some points.
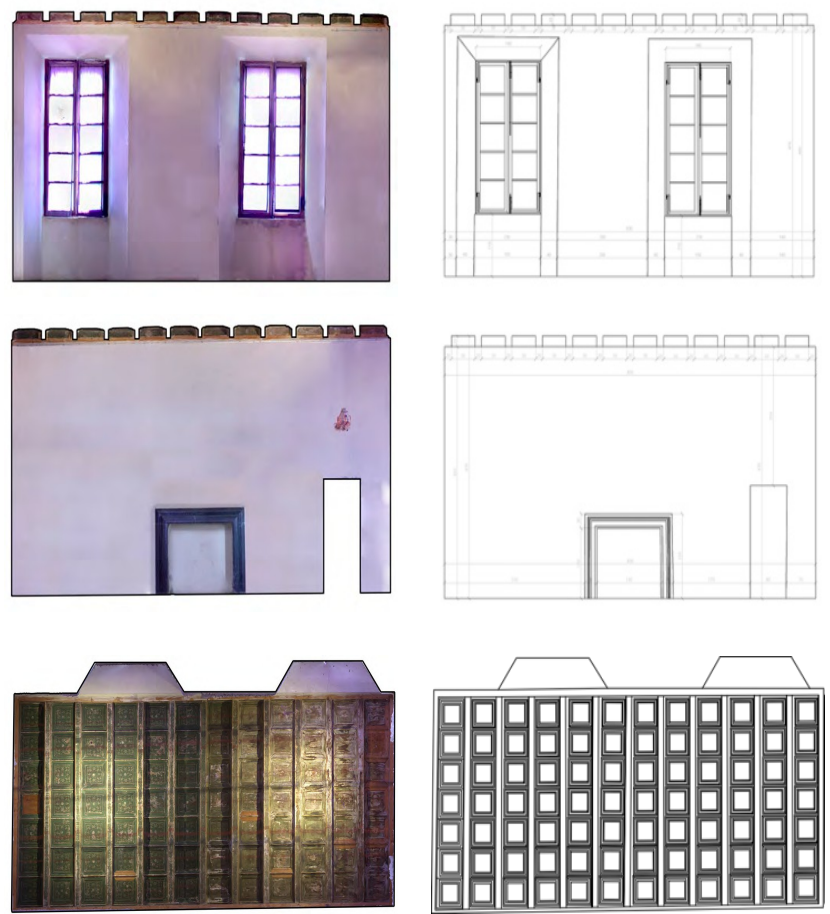

Figure 11. Sections of the room (by photos and by lines) and ceiling coming from Photoscan projections

\subsection{Passage room}

\#ROOM 17

This room (Figure 11-12) adjacent to the Sala degli Imperatori, has a fairly simple decoration, only limited to the ceiling. Built in wood and polychrome, there is a clear degradation due to moisture problems that need adequate intervention.

With a fairly abundant light coming from the two windows of a side wall, this diaphanous space offers a large number of possibilities for different uses. Other degradations can be observed in the walls close to the windows.

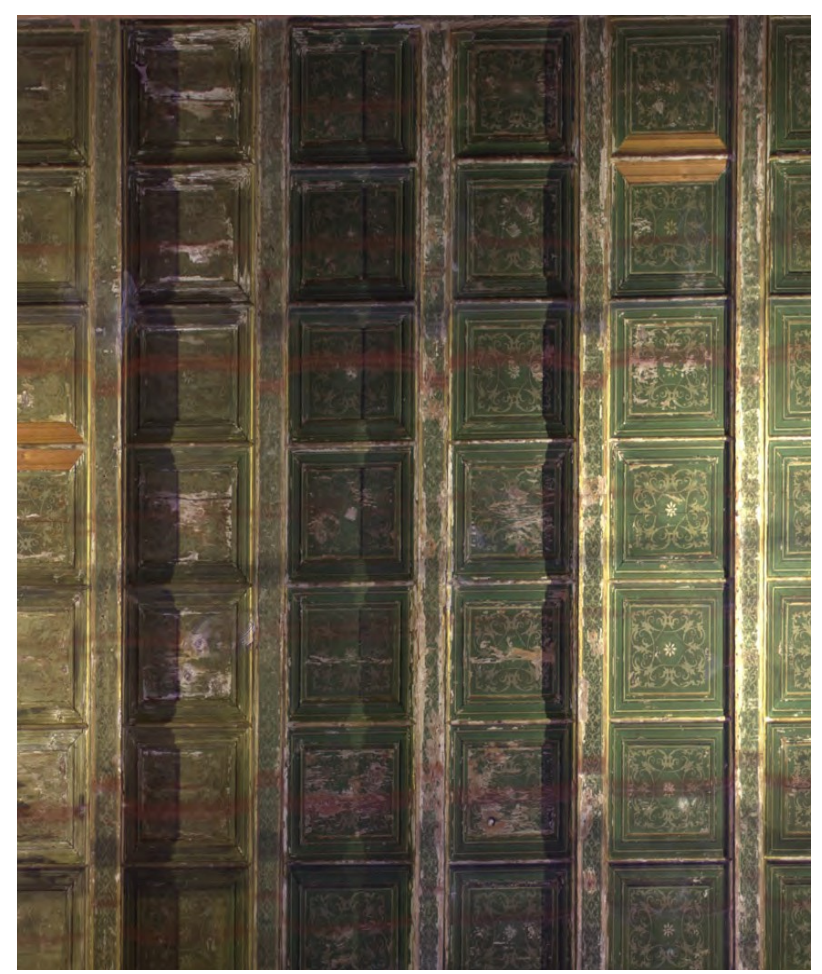

Figure 12. Detail of the ceiling coming from Photoscan projections

\subsection{Sala degli Antenati}

\section{ROOM \#03}

The room number \#03 (Figure 13-14-15), the Sala degli Antenati, also known as Libreria Piccola, which once housed the palace's most valuable books and cabinets with a series of marble and copper statues, a collection of coins and ancient medals and whose authorship is unknown, it is traditionally attributed to the painter and sculptor Alberto Cavalli, who is known to have lived in Sabbioneta from 1570 until his death. It was Vespasiano who commissioned the representation of his predecessors in bas-relief on the sides and the vault decorated with embroidered laces and stuccos of different motifs.

Regarding the internal space, its rectangular geometry, accentuated by the side light provided by the window and the semi-cylindrical ceiling creates a canyon that invites the visitor to the balcony.

a) The lighting system is in this room even more strong. The direct light projected towards the statues creates strong contrast and a not harmonic vision of the space. However, it also provides interesting ways to strongly show volumes at certain points.

b) The statues do not seem to present defaults in their volume. The color is not homogeneous in the frame's background.

c) The rosette in the principal elevation could held another ornament, like a bust.

d) The colorful composition of the ceiling contrasts to the rest of the room. 

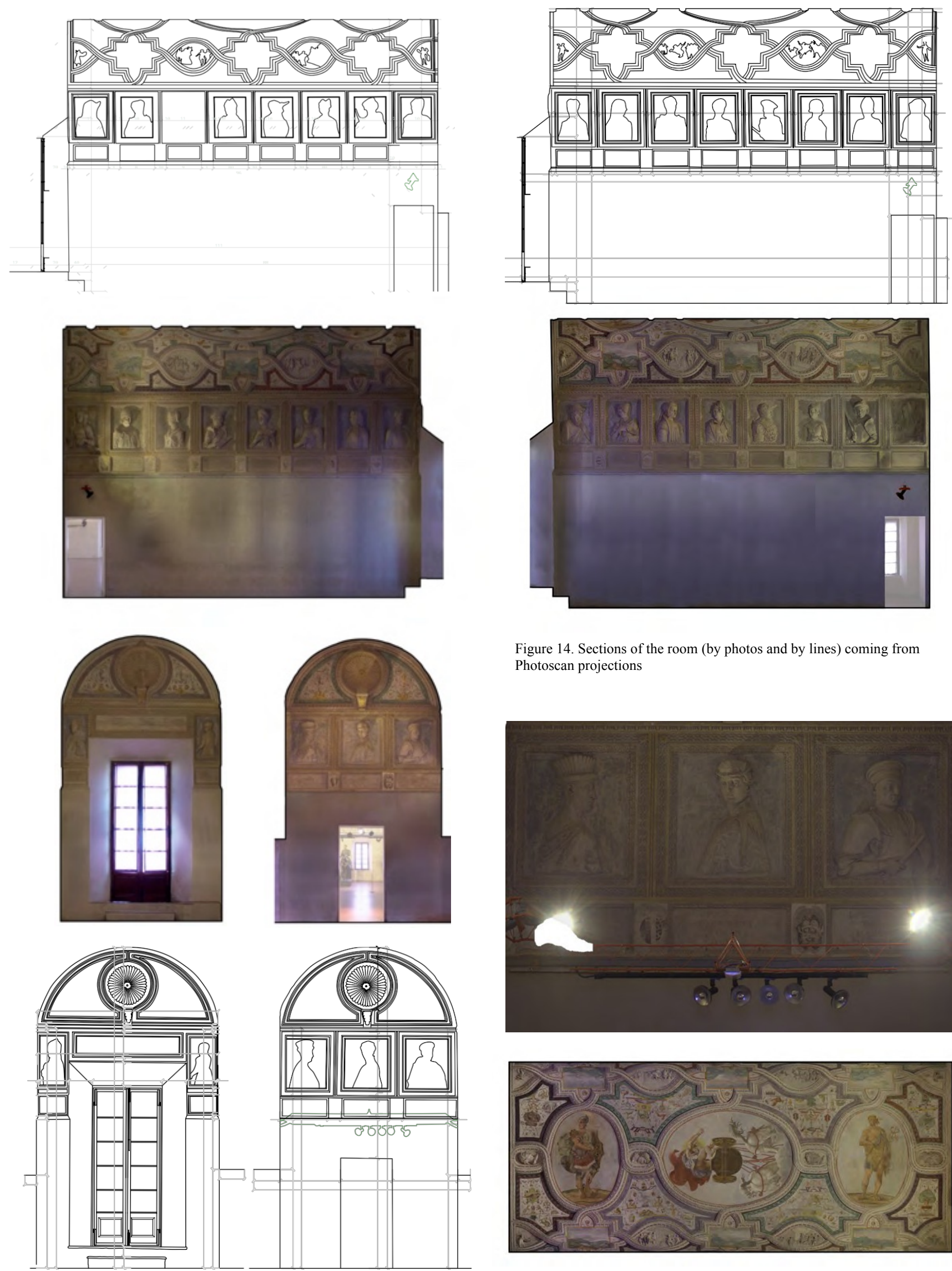

Figure 14. Sections of the room (by photos and by lines) coming from Photoscan projections
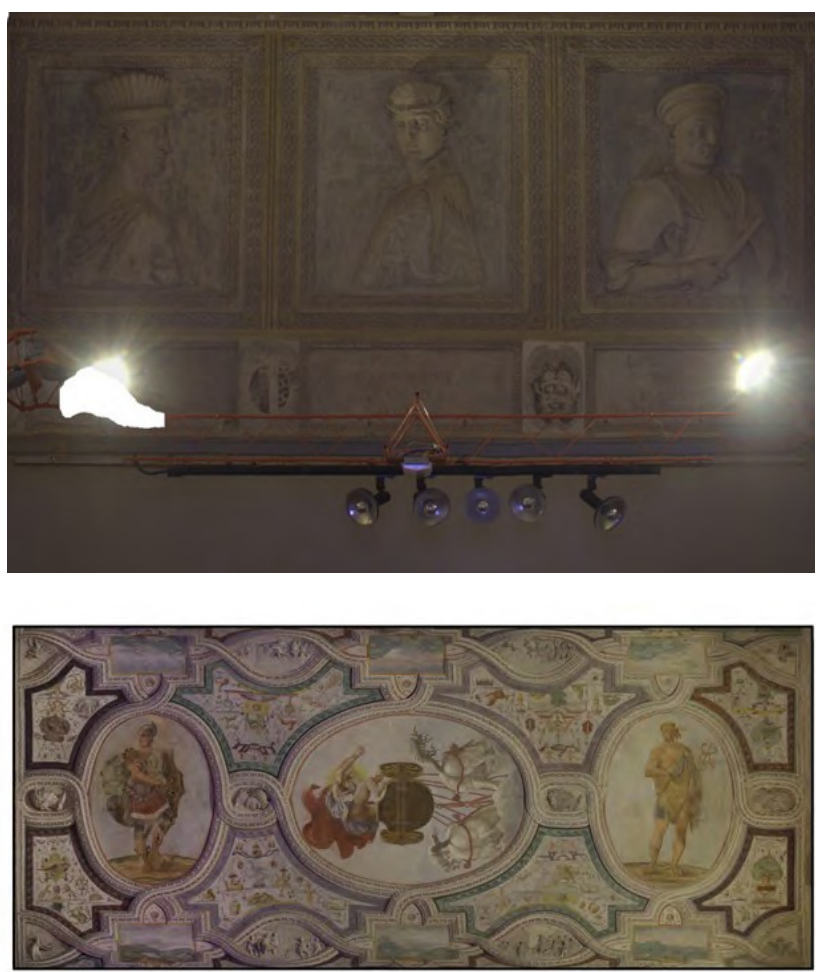

Figure 13. Sections of the room (by photos and by lines) coming from Photoscan projections

Figure 15. Details of the room and ceiling coming from Photoscan projections 


\section{CONCLUSIONS}

The application of photo-modelling to case studies has led to understanding the versatility and the manageability of this process, producing satisfactory results with minimal equipment and budgets. Furthermore, it is evident that in a short time it is possible to obtain a photorealistic model that already provides from a first analysis much information regarding the materialsuperficial, geometric-semantic aspects of an architecture. With models you can perform animations or produce threedimensional views, you can explore them internally to display software, perform measurements, extract section profiles, disassemble them to describe the semantics or topological reports of the architecture, or extrapolate orthogonal, axonometric, perspective views exploiting them as basis of the design which is often the last means of transmission of the survey. The threedimensional models generated allow to freeze the moment of capture by describing the state of affairs no longer as a sequence of images but as a single system with spatial relations, providing a tool that is effective, manageable and useful for future research.

\section{REFERENCES}

AA. VV., 1989. Giulio Romano. Electa, Milano, Italy.

AA. VV., 1999. T.C.I.. Lombardia, Italy.

Apollonio, F.I., Gaiani, M., Zheng, S., 2012. BIM-based modelling and data enrichment of classical Architectural Buildings. In: Vol.2..CASPUR-CIBER (Ed.), Ricerca Scientifica e Tecnologie dell'Informazione, Rome, Italy, pp. 4162.

Battini, C., Vecchiattini, R., 2018. Immagini HDR per la documentazione tridimensionale dei manufatti storici. In: R.Salerno (edited by), RAPPRESENTAZIONE / MATERIALE / IMMATERIALE DRAWING AS (IN)TANGIBLE REPRESENTATION. $15^{\circ}$ Conference UID Milano 2018, $40^{\circ}$ international conference of teachers of the disciplines of representation, Gangemi, Rome, Italy, pp. 311-318.

Bertolaccini, L., 2010. Mantova e Sabbioneta. Libreria dello stato, Istituto poligrafico e zecca dello stato. Roma, Italy.

Cipriani, L., Fantini, F., Bertacchi, S., 2014. The international Archives of the Photogrammetry, Remote sensing and Spatial Information Sciences, Volume XL-5/W2. In: ISPRS Technical Commission V Symposium, 3D Models mapping optimization through an integrated parametrization approach: cases studies from Ravenna, Riva del Garda, Italy, pp. 173-180.

De Luca, L., 2011. La fotomodellazione architettonica. Rilievo, modellazione, rappresentazione di edifici a partire da fotografie. Flaccovio Dario, Palermo, Italy.

Di Tondo, S., Fabrizi, E., 2013. Disegnare con la fotografia digitale, Metodologie e tecniche di fotomodellazione a confronto: il caso del Tempio Grande di Abu Simbel, Vol. 6, n.12. DisegnareCON, Bologna, Italy, pp. 1-12.

Ferri, E., 2006. Il sogno del principe Vespasiano Gonzaga e l'invenzione di Sabbioneta. Le Scie Mondadori, Milano, Italy.

Tellina Perina, C., 1993. Sabbioneta. Electa, Milano, Italy.

\section{ACKNOWLEDGEMENTS}

We would like to thanks the students Yunus Alperen Basaç, Martín García Pérez, Javier Jiménez Borona, Fikri Umut Yener of the Course of Architectural Preservation Studio of the Politecnico di Milano (YY 2017/2018) for their survey drawings realised under the supervision of the Proff. Alessandro Bianchi and Davide Del Curto. Moreover, we would like to thanks the cooperation and the kindness of the staff of Palazzo Ducale di Sabbioneta for the availability to hosting the students of the course. 